\title{
VALUE NETWORK AS PART OF NEW TRENDS IN COMMUNICATION
}

This paper deals with the topic of value network importance for the new trends in communication. It describes the main definition of distribution and place, and their relations with the value network. The value network is described as a network of all relevant factors impacting the product where the product is in the network's centre. The case of Apple iPod is provided as an example of the value network. E-commerce and digital distribution are also described in the paper as new communication trends. Discussion deals with main text results and authors' opinions.

Keywords: marketing, management, value network, distribution, communication, new trends, innovations, point of sales, digital distribution, e-commerce.

\section{Introduction}

In the time of globalisation, internetisation, social networks, information spreading and new way communication the ability to make up something new, creative, efficient and unique is a key factor of success. It is something which can bring higher value for customers and other stakeholders. The chance to come to the market with an idea which nobody has ever had yet, nobody has had it patented or even nobody has run business with it seems to get smaller and smaller. Just open the Internet and the idea which seemed to be a discovery may suddenly lose its potential rapidly in global competition.

Innovations have an essential role in the current economic, political and social transformation of developing companies and countries. We can look at innovations from a few points of view. We can talk about the product innovation (including the products and services the specification or intended use of which differs from previous company products significantly), process innovations (occurring in industry as well as in services and including the new or improved production methods, logistics, supplier and distribution systems), organisation innovations (implementation of important changes in business practice, organization of working duties and a process of making decisions), marketing innovations (important changes in the way of trading with products and services including design and package changes) $[1,2,3]$.

A complex view which connects all above mentioned kinds of innovations is important here. It is not easy to innovate at all as shown by the results gained by the authors in cooperation with the entrepreneurship practice as the co-providers of the project Innovations - the Way to Increase Competitive Ability and Regional
Development (cross-border cooperation program Slovak Republic - Czech Republic 2007 - 2013, ITMS 22410420011). Therefore we want to discuss value networks in this paper and we want to point at some examples from abroad how innovatively some wellknown foreign companies have dealt with this issue and to inspire a lot of our companies. In the time when the examples appeared, they embodied interesting and innovative solutions.

\section{Introduction to the topic}

A traditional definition describes distribution as a complex of activities whose goal is to make a finished product available for customers. The distribution comprises [4, 5, 6, 7]:

- Processes of physical relocation - the purpose of distribution is to transfer a product in the right time to the right place. Physical distribution includes transportation, storage and inventory management;

- Changes in proprietorship - the change of proprietorship of the product occurs at least once in a distribution process (in case of so called direct sale, i.e. the sale performed directly between a producer and a final consumer, to compare with the indirect sale, in which a product goes through several processes of the sales and purchase on the way to a consumer: e.g. whole-sale companies - retail companies - consumer);

- Other activities - we mean e.g. gathering of marketing information, advertisement, insurance, loaning etc. These are the activities which are not involved in the previous processes directly; however, they create conditions for their smooth running.

Such activities are performed either by the producer or by different organizations which constitute so-called distribution net-

\footnotetext{
* Jakub Soviar, Josef Vodak

Department of Management Theories, Faculty of Management Science and Informatics, University of Zilina, Slovakia,

E-mail: jakub.soviar@fri.uniza.sk
} 
work. The distribution network forms a framework to perform the functions such as purchase, sales, storage, transportation, goods movement financing, risk resistance, marketing information providing. The distribution network consists of the following independent participants such as producers, distributors, sales organizations (whole-sale and retail organizations) and other organizations intended to perform specialized (supporting) activities [8, 9, 10, 6, 7]

According to the above mentioned we can say that successful business (marketing) process depends on a lot of factors. One of the most important factors, after the value creation for a customer, is its delivery. [11] In general we distinguish the following ones $[10,12,6]$ :

- Value network: a complex process which includes necessary information inputs, inputs for the transformation process, partnership relations, delivery of the value to the customer, feedback etc.

- Marketing distribution channels (complex logistics chain): particular elements of distribution network, their quantity, quality and management (technology, processes, people, organization, operation ...).

- Parameters of a place where a customer meets the product: physical attributes of the place (architecture and geographical location), education and behaviour of the personnel, parameters and possibilities of the web site etc

\section{Distribution Channels and Value Networks}

"Marketing distribution channels are a set of mutually dependent organizations engaged in the process of making a product or service available for use or consumption from the formal point of view. It is a set of ways of releasing a product or service after having been made and which finishes by their purchase and use by the final user" $[10,12,6]$.

Every company should make a strategic decision on the importance of particular channels. That means to specify their importance and thus the rate and intensity of their management. Utilisation of the complex channels can decrease costs and vice versa. The same applies for a direct channel. According to relevant literature [10 $12,6]$ the participants of branched distribution channels earn approx. $30-50$ percent of the final purchase price of a product [6].

The process of the DELL company is a good example of reassessment of the importance of the marketing distribution. The company was established in 1984 as a "student IT company". Their business model was built on direct distribution. They used catalogues. Orders were made by post and later on by telephone. In that time that was an important innovation. A customer built a computer and accessories himself. The order was delivered where he had stated. Already in that time DELL started to develop their unique service and guarantee conditions. That completed the model of direct distribution and significantly affected customers' satisfaction positively. DELL started the sales via the internet in 1996 which enabled even higher comfort when configuring the orders and their updates. However, the development on the market caused that the competitors of the company DELL, who used distribution through the chain of brokers started to increase their market shares and profit at the expense of DELL. That was caused especially by:

- Increase in shopping in shopping centres and chains. Customers buy the products which are available on the places where they move most often.

- Possibility to show the product next to the competition. In retail shops the products are next to each other. A customer may choose immediately according to his preferences.

- Cost saving. Direct distribution may have extra high costs. When distributing through a chain of brokers it is possible to decrease a big part of such costs. E.g. personnel costs, database administration costs etc.

- Access to new/other customers. The distribution through the chain of brokers brings the product closer to customers. It brings it to the places where the customers, who would not be affected by the distribution channel, move.

The above mentioned facts results in the state that the competition and market development have changed the situation significantly. DELL had to respond to it by the change of the distribution channels importance. Nowadays they are operating a direct channel as well as distribution through a chain of brokers.

Within the distribution channels we talk also about their development. It is establishing, development and leaving the channels regarding to company goals and market development. That means their complex management. The example of DELL relates also to that phenomenon. A common example is a "brick and mortar" computer shop in a Slovak or Czech town. It is a communication and distribution channel for the customers from that town. If it makes an e-shop, another distribution channel, it can cover the national market, gain more customers, get closer to the competition etc.

Another real example of the distribution channels development is the process of the Coca Cola company. It is a global corporation which has already expanded to the whole world. At such expansion it must use and work in local conditions and use local resources (inputs, people...). Therefore they build local production and distribution centres in strategic locations which are able to cover the given market with their production and distribution. Coca Cola themselves have specified the target destinations of their products, i.e. the places where they desire to sell their products to target customers:

1. Retail food and mixed goods shops (super and hyper markets, small shop unions etc.)

2. Drink machines (located in schools, public areas, waiting rooms, in different companies etc.)

3. Hotels, restaurants, cafes, including "fast food" etc.

4. Mobile sale (any mobile sale where drinks may be offered or solely drinks are offered)

5. Amusement parks (water parks, theme parks such as Disneyworld etc.) 


\subsection{Value Networks}

In its wider meaning the company is in the centre of the value network. It forms a system of partnerships and alliances concluded by the company in order to supply and deliver its offer. The value network includes company suppliers and their suppliers, also company direct customers and final customers. The value network also includes value relationships with other essential entities (stakeholders) such as research centres, particular researchers at universities or governmental inspection bodies [10, 12, 6, 13, 14].

It is a relatively new concept built on a complex system approach. It deals with all relevant events which affect the process of value creation and delivery. The example of the product of the company Apple, a well-known and popular iPod, may serve as a good example. It is a simplified model of the value network shown in the following Fig. 1.

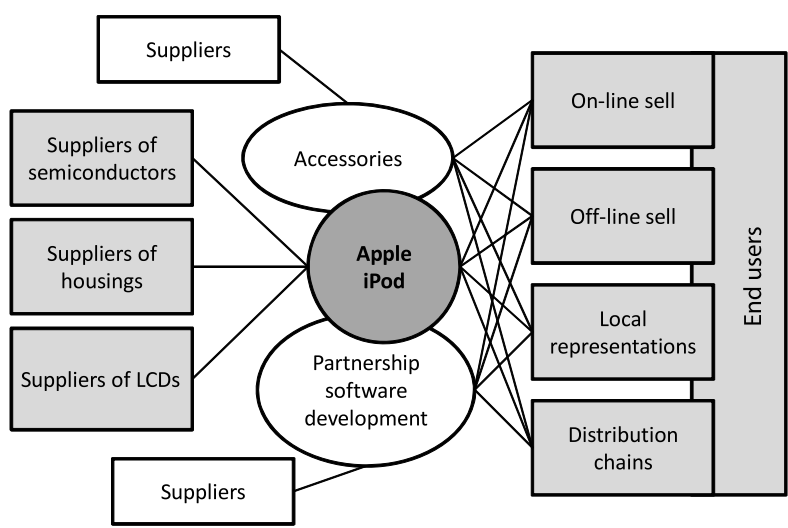

Fig. 1 Example of a value network (own solution)

The product, iPod, is in the centre of the value network. On the left there are suppliers of the main parts needed for physical production of the product (suppliers of semiconductors, covers and LCD displays). In the centre there are, together with the product, partners who must cooperate with the company closely, since their products and connected with iPod directly. They are the producers of original accessories. If this is to be licensed by the Apple company, it has to meet specified technical standards. The software producers must also cooperate with the company closely. Their applications must go through testing and must be certified. In both cases there is an advantage that the products (accessories and software), after having met the conditions, will be included in the official Apple distribution network. Here we have gotten to the distribution ways of the product shown on the right. In case of iPod that can mean the official channels of the Apple company or their partners. The product is available also in free distribution which means they can be the distribution channels completely independent from Apple. Each above mentioned distribution system is interconnected with particular final customers.
Apple is thus able to satisfy the demand in a global rate. Feedback has not been shown in the figure. Of course, there is feedback. It is the most intensive between directly interconnected customers and producers of the accessories and software used by the customers.

\subsection{Design and Principles of Distribution Channels Management}

Let's look at the basic categories of the decisions which must be made by the management regarding to the marketing channels design. They are the categories which will be filled with particular contents in a given case $[10,12,6]$ :

1. The analysis of the levels of the provided services required by the customers. The analysis focuses on the amount, waiting and shipping period, territorial coverage, product diversity and additional services

2. Setting the goals and limitations. On the basis of the results of the analysis exact goals regarding to the distribution are set. Limitations, e.g. financial, personnel, quantity ones can be stated, too. In fact they further complete and specify the stated goals.

3. Identification of main variants of the distribution channels

- Types of brokers - particular brokers who will perform the work in particular distribution channels (people and organizations)

- Number of brokers

- Exclusive distribution - used in the case when the producer wants to keep intensive control of his product. It is represented by strict and exact limitation of the number of brokers. The producer defines who can distribute his products. It is often used with exclusive goods and luxurious brands (e.g. Gucci, Versace, Lamborghini etc.)

- Selective distribution - only a few brokers are used, not all of those who want to distribute or sell the product. The producer may define the criteria. Middle rate of control.

- Intensive distribution - the producer wants to get his product into as many shops as possible. The lowest rate of control. It is used especially at common consumer goods such as cosmetics, sweets etc.

- Conditions and obligations of the distribution channel members. The producer can specify them and check if they are observed. The possibilities are derived from the producer's prestige and economic power.

4. Evaluation of the main alternatives. It is proper to prepare a few variants of the distribution system. Then those ones which can best fit to the specified goals and possibilities may be chosen from the available possibilities.

- Economic criteria related particularly to the efficiency.

- Rate of control and adaptability, i.e. what rate of control of the distribution channels the producer wants to have; what are the possibilities of the distributors to adjust to new or modified conditions (e.g. new products, new technical documentation, modified warranty conditions, etc.). 


\subsection{Point of Sales}

In this case we are talking about the place where a customer meets the product. Usually the physical attributes of the area are concerned, i.e. the architectonic solution of the exterior, interior, as well as its geographic location. In its wider meaning we can talk about the personnel offering the product parameters, i.e. their abilities, knowledge, behaviour, clothes, appearance etc $[4,8,9,10$ $12,6,13,7,14]$. Nowadays it is of course also the level of the web sites where the products can be ordered or where the information about them can be found (limpidity, information, possibility to order and pay, possibility to provide feedback, graphics, design etc.) [5]. A complex view therefore takes physical, design, technical and personnel parameters into consideration - their level, quality and quantity.

The sales point in the direct control of the Apple company can serve as a good example. They support, by all their parameters, the image and philosophy of the company in form of care for the Corporate Identity. The company premises are situated in city centres, they have modern architectonical solution corresponding to design principles of the company, the staff is highly motivated and their relationship to the company products in very close.

The similar example from a different industry is represented by official branded car services of the Toyota company. The company has specified a few principles the satisfying of which is a matter of course. The walls and floors are shiny white and the whole premises are maintained extra clean. This has a positive communication effect on a customer. Connection with cleanness and preciseness is made here.

Upon the above mentioned facts we can state that the parameters of the place where a customer meets the product have an essential effect on the internal and external communication of the organization [15]. Such parameters affect especially the image (of the product, brand, company, operation...), position of the brand (regarding to the competition, customers), satisfaction of a customer (potential and measured) or self-specification regarding to the competition (especially differentiation).

\subsection{E-commerce and Digital Distribution as Current Trends}

Information and communication technologies and their development change the market substantially. Usually very rapid changes are concerned. There is a new, non-physical value in form of digital contents there. It can have a form of the data, software, music, video, games etc. the word "multimedia" is often used in this meaning. New innovations from new technologies, methods and opportunities can bring significant benefits to an enterprise [16]. Regarding to the distribution we talk particularly about electronic trade and electronic distribution.

The following are defined as basic terms related to this topic: E-business (designates utilisation of the electronic means and plat- forms for the purpose of business), E-commerce (a company or a web site offers or sells products on-line), E-purchasing (a company purchases goods, services and information from different suppliers on-line) and E-marketing (a company informs purchasers, communicates, promotes and sells their products on the Internet) [6].

The business model of the Amazon company can serve as a good example of e-commerce. It started in 1995 as a so called "pure-click" company, that means the company focused on solely on-line ordering system through their web site. Originally it was a book shop. Step by step they have extended their range of goods. Nowadays they are selling and distributing almost all portfolios of consumer goods (e.g. clothes, electronics, cosmetics...). Their competitive advantage was their sole focus on the Internet. Their sales point is their web site. That was just here where they have brought the following essential innovations:

- As the first ones they made it possible to comment and evaluate the products being sold. A user had to register. Everyone could see the evaluation. They started to make the product charts according to the users' evaluations. The customer thus got bigger trust to a then new form of shopping. At the same time they attracted new customers who were looking for some information regarding to the use of some products etc.

- The company started to gather the data on their customers. Since the registration is required, they monitored the facts such as what the person looks for, what he comments, how he comments, how often he buys, what amount he spends etc. Upon such data Amazon adjusts the offer, customizes the offer for the particular person.

- Nowadays Amazon has expanded also in the digital distribution of music, games and electronic books (described further in the text).

Digital distribution is an intensive trend of these days. Technical possibilities of communication networks are still getting bigger. The development since 2000 in the Slovak Republic can serve as a good example. Internet connection was then made mostly using the Dial-up technology with the theoretical highest transmission speed of $56 \mathrm{~kb} / \mathrm{s}$. Nowadays mobile and optical networks are common. In 2010 the average connection speed was 10, $18 \mathrm{Mbit} / \mathrm{s}$ in Slovakia [17]. The price of such connection is the same as for Dial-up in 2000, often even lower. The data storage places such as hard disks have undergone the similar development. Their capacity has been increased significantly and their price has been decreasing permanently. In 2000 common hard disks had the capacity of approx. $1 \mathrm{~GB}$. The capacity of the current hard disks is normally in the range of terabytes.

Videogames, music, films, software and data form digital contents. As it has been mentioned above, the technical capacities today enable their on-line transmission. We can see here a sudden regression of physical media (CD, DVD etc.) and sudden launching of on-line distribution, cloud computing, video on demand etc. Mobile devices participate in this trend and support it. A mobile phone has not been only a communication device now. It is a centre of personal joy and planning. The contents distributed through the communication networks to final users is a product - it makes value. 
Without applications, or music and video such technologies are irrelevant. The demand in this area tends to rise, especially in the area of digital joy.

The products of the Apple company are a good example of utilisation of the digital distribution as a competitive advantage Particularly the products iPod (digital mobile music player) and iTunes (software for administration and purchase of music and video) are concerned. Apple noticed enormous users' demand for music distributed through the Internet at first in the MP3 format However, such demand was satisfied illegally. Therefore Apple created a legal solution. It offered a complex product in form of a mobile player and a software, which enabled buying music onlone simply and legally. The products were interconnected regarding to the function - they supported each other. E.g. the first generation of the players, launched on 23/10/2001, was equipped with the FireWire interface, which is the Apple's patent and a competitor of USB. FireWire was used in the computer platform MAC, at PC this interface was rather an exception. Of course there was a fact that the player required the cooperation with the iTunes software for its proper function, e.g. when transferring music from a computer to the player etc. The products were made in accordance with the philosophy of Apple. There was an emphasis on the design of the player and function of the whole solution. This was really high - however, it required the using of the whole platform from Apple. We can say that Apple satisfied a real need on the market in form of the first commercial system of the digital music distribution. They became market leaders and they have not lost this position so far.

Another current and suitable example is a digital distribution of books of the Amazon company. Amazon sells cheap, simple electronic book reader based on the e-ink technology. This technology simulates real paper and is extra energy saving. The reader is supported by the on-line sales of electronic books. The system is comfortable for the users and enables to send the purchased titles directly to the particular reader to the particular user. We can say that Amazon was inspired by the process of Apple in case of iPod and iTunes. However, their solution is more open. The reader supports standardized formats and no special software is needed to download books to the reader. Amazon even provides free text conversion to the needed format on-line and free of charge. Let's look at some data regarding to the market success of this model [18]:

- In 2010 Amazon sold 143 electronic books for the Kindle reader for each 100 classical books.

- Net income from sales in 2010 achieved USD 12.95 billion, which means the inter-annual increase by $36 \%$ to compare with the fourth quarter 2009.

- Net profit increased by 8 percent to USD 416 million interannually (2009 - 2010).

- Income from sale for the whole calendar year 2010 reached USD 34.20 billion.

- Net profit was by 28 percent higher inter-annually (2009 - 2010) and reached the level of USD 1.15 billion.

\section{Discussion}

The development of the information-communication technology (ICT) has changed the whole society. The distribution processes are not an exception. The traditional attributes have not lost the importance, however, the significant influence of ICT is obvious e.g. at placing orders, monitoring of the way of the goods, warehouse management, logistics etc. Produced values with significant demand have also moved to the digital world. "Proper use of ICT can significantly affect the creation of business strategy [19]." The data which we make are often more valuable than the hardware we work with etc.

The above facts result in a few basic recommendations related to the current issues of the value distribution:

1. Focus on stakeholders, i.e. the entities which are essential for the organization and able to affect it significantly, is important $[20,13]$. The distribution chain, sellers, web sites administrators, companies providing the hosting and functioning of the web site or orders... these all are important stakeholders. Therefore, it is necessary to specify, clearly and exactly, who are our stakeholders and what value they expect.

2. The analysis of the possibilities to make a base and initial point for distribution ways planning. Today's market provides a lot of ways to distribute the value more efficiently or to target more customers or to target a specific group of selected customers etc.

3. A complex view to the production and consumption of the values comes from the system approach. The value network is a suitable help to understand the importance of individual relationships, communication and their subsequent control.

4. Particular distribution channels have different importance and different value. According to these attributes, which should be known at first, it is then necessary to approach the management of the relations within the given channels.

5. Physical attributes of the place where a customer meets the product affect his decision and satisfaction.

6. The Internet and mobile communication are a matter of course today. At least basic Internet support is suitable for almost every company.

7. Web site is a communication platform. It represents the corporate and product image. Its quality and services which it provides affect the customers' decision and satisfaction.

8. The Internet and mobile communication represent a possibility how to expand, how to get more customers.

9. Internet trade and digital distribution are strong trends. Digital contents is very attractive for people. It is important to care about the current, comfortable and safe possibilities of its distribution to the customers.

10. The distribution does not refer only to the product itself but also the corporate values and Corporate Identity. Therefore, we cannot forget that the additional services to the products such as consulting, information, warranty, complaints, installation, trainings etc. are concerned, too. This all can mean a significant competitive advantage. 
We should realize that there is not a single clearly best way of distribution. Combination of them is often suitable, e.g. a direct channel, a chain of brokers and Internet support. The fact that the only guarantee is a guarantee of change applies, too and the same applies also for the communication with a customer and distribution of value for a customer and for stakeholders. We could realize such changes at the above mentioned examples of the global companies.

\section{Conclusion}

We have discussed the distribution, value networks and utilisation of the information communication technology in innovative approaches to communication and value supply for stakeholders in the papers. The article was intended to stimulate the concerned to think about the fact how it is possible to modify the current approaches of companies creatively into a new quality in form of the examples.
The value for a customer will not be a value which he requires if the distribution does not contribute its share. The focus on the idea of the value network may be interesting for a lot of our companies (therefore also this article), on the other hand we should realize that creative and innovative approach is necessary and very important also in this case.

Unfortunately a lot of our companies cannot see anything in our ideas presented above which we should deal with intensively today. It is often caused by the fact that a lot of them have their energy focused on many operative activities and they have not created enough space for strategic thinking e.g. in form of the study of the best practices to the distribution and value networks.

\section{Acknowledgements}

This paper was supported by the Slovak scientific grant VEGA 1/0992/11 2011-2013.

\section{References}

[1] STATISTICAL OFFICE OF THE SLOVAK REPUBLIC, 2012.

[2] PRO INNO Europe ${ }^{\circledR}$. www.proinno-europe.eu. 2011.

[3] VODAK, J., SOVIAR, J: Innovation needs of Corporations in Zilina Self-government Region and Moravian-Silesian Region. In Borkowski, S., Konstanciak, M. Toyotarity. Quality in the Toyota's management principles. Monography. Samara, p 202-226, 2011.

[4] BAINES, P.: Marketing, Oxford University Press. 2008.

[5] DORCAK, P., POLlAK, F.: Marketing \& e-business: How to Orient in New Marketing's Terms and Processes (in Slovak), Presov, EZO.sk, s.r.o., 2010.

[6] KOTLER, P., KELLER, K. L.: Marketing Management (in Czech), Prague : Grada, 2007.

[7] STRISS, J., VODAK, J., KUBINA, M., JANKAL, R., SOVIAR, J.: Marketing Management (in Slovak). University of Zilina, 2009.

[8] HAVLICEK, K., KASIK, M.: Marketing Management of Small and Medium Enterprises (in Czech), Management Press, Prague, 2005

[9] KERIN, R., PETERSON, R.: Strategic Marketing Problems. Cases and Comments, Pearson, 2009.

[10] KOTLER, P., CASLIONE, J. A.: Chaotics: The Business of Managing and Marketing in the Age of Turbulence (in Czech), Prague : Computer Press, 2009.

[11] KUMAR, N.: Marketing as Strategy (in Czech), Prague : Grada, 2008.

[12] KOTLER, P., JAIN, D. C., MAESINCEE, S.: Marketing Moves (in Czech), Management Press. Prague, 2007.

[13] ROBBINS, P, S., COULTER, M.: Management (in Czech), Prague : Grada, 2004.

[14] TROMMSDORFF, V., STEINHOFF, F.: Marketing of Innovations (in Czech), C. H. Beck, 2009.

[15] SOVIAR, J.: Event Marketing (in Slovak), Trends of Marketing Communication, European Polytechnic Institute, Kunovice, p. 45 - 58, 2009.

[16] TOKARCIKOVA, E.: Influence of Social Networking for Entreprise's Activities, In: Periodica Polytechnica, Social and Management Sciences, 19/1, 2011.

[17] ZIVE.SK (online). (1. 2. 2011) http://www.zive.sk/sr-je-v-rychlosti-internetu-na-30-mieste-provideri-vraj-dodrzuju-co-slubia/sc-4-a291645/default.aspx

[18] DSL.SK (online). (1. 2. 2011) http://www.dsl.sk/article.php?article=9463; http://www.zive.sk/elektronicke-knihy-pre-amazonkindle-prekonali-tlacene/sc-4-a-292162/default.aspx

[19] LENDEL, V., VARMUS, M.: Innovative Potencial of Strategy, Scientific J. Economics - Management - Innovations, Moravian university Olomouc, vol. II, No. 1, 2010, p. 47-53, ISSN 1804-1299.

[20] PORTER, M.: On Competition, Boston, Harvard Business School, 1998. 